\title{
Understanding implicit learning in museums and galleries
}

\author{
Alex Elwick*
}

\begin{abstract}
Implicit learning, learning we are not aware of, or learning which results in knowledge we do not know we possess or cannot articulate, is often considered to be a ubiquitous part of life, and yet is rarely studied in real-world contexts. This paper presents an attempt to research implicit learning amongst museum and gallery visitors, with the ultimate aim being to understand whether implicit learning takes place in the museum and how we might begin to unearth such tacit (silent) knowledge. Examples drawn from interviewees with members of gallery 'friends' associations provide evidence that people often possess knowledge they are seemingly unaware of, directly derived from their museum/gallery experiences. The methodology explored here acts as a formative means to study implicit learning and the paper suggests how this might be further developed.
\end{abstract}

Key words: Implicit, tacit, non-formal, informal, learning.

\section{Introduction}

This paper will address the concept of 'implicit learning' - learning we are not aware of, or learning which results in knowledge we do not know we possess - in the museum and gallery. It is argued that understanding the implicit learning processes that take place when a visitor steps through the doors of a museum is likely to contribute to a greater understanding of the entire visitor experience. Museum and gallery education departments, as well as curatorial or exhibition staff, might be better enabled to cater for the learning needs of those who visit through such understanding. The dominant perspectives of learning in museum studies often centre around explicit learning experiences which can be measured or codified (e.g. HooperGreenhill et al. 2003). Although the diverse aspects of non-formal learning are addressed by some commentators (e.g. Leinhardt and Knutson 2004, Falk \& Dierking 2000) such approaches rarely consider implicit learning.

Implicit learning has long been studied in psychology and yet, within museology, is rarely acknowledged as a fundamental constituent of the learning experience undertaken by visitors to museums or galleries, despite its ubiquity. Eraut's (2000) influential tract on non-formal learning underscored implicit learning as one of the three pillars which formed his typology of the concept. When considering the non-formal visitor experience it should be acknowledged, he argued, that people will learn in an explicit, deliberate and conscious way; but they will also undertake non-deliberative learning, which they may or may not be aware of (Eraut 2000). It might be relatively straightforward for a museum educator to prepare a display which targets this deliberative learning, but maximising the potential of implicit learning experiences is much less straightforward.

This paper attempts to highlight the ways in which people learn implicitly and should act as a prompt for museum educators when considering the different ways in which their visitors learn. It will begin with a discussion of the theory surrounding implicit learning - drawn largely from non-museological disciplines, since they offer a much more comprehensive literature base.

In order to study the phenomenon of implicit learning, in-depth qualitative interviews with eight participants were carried out; all the participants were regular gallery visitors (those belonging to 'friends' groups ${ }^{1}$ ). The data was analysed thematically in order to identify contradictions in participant's responses which might be examples of implicit learning. 


\section{Theory}

This section will outline existing definitions of implicit learning and present a case for adopting a broad definition in terms of investigating the concept in the context of museum and gallery visiting. The two key debates amongst theorists of the topic revolve around whether implicit learning is inherently different from explicit learning; and whether the definition should focus on the process itself (i.e. learning one is not aware of) or the product created (i.e. knowledge one does not know one possesses).

As one of the leading proponents of implicit learning, and one of the first authors to really investigate the phenomenon, Reber defined it as 'the acquisition of knowledge that takes place independently of conscious attempts to learn and largely in the absence of explicit knowledge about what was acquired' (1993: 5). Reber argued that implicit learning was a fundamental process that 'lies at the very heart of the adaptive behaviour repertoire of every complex organism' (1993: 5). Interestingly, he also argued that explicit and implicit learning should not be treated as separate processes (what he described as the 'polarity fallacy'), but instead should be viewed as interactive and connected (Reber 1993: 23).

In terms of establishing what, exactly, implicit learning is, Reber's definition placed emphasis on a lack of conscious awareness regarding both the learning and the resultant knowledge (1993). A similar view was taken by Dianne and Dienes, who pointed to the ability of people to learn about the structure of everyday environments, which can be quite complex, 'without necessarily intending to do so, and in such a way that the resulting knowledge is difficult to express' (1993: 2); they described implicit learning as the links between stimuli and actions which one is not aware of (Dianne and Dienes 1993: 13).

Frensch suggested that implicit learning should be defined as 'the non intentional, automatic acquisition of knowledge' (1998: 48); and Buchner and Wippich stated that 'implicit learning refers to the acquisition of knowledge about the structural properties of the relations between (usually more than two) objects or events ... knowledge acquisition is incidental' (1998: 6).

Eraut (2000) identified implicit learning as one of the three key types of non-formal learning, whilst also highlighting the linked concept of tacit knowledge. He described tacit knowledge as 'silent' knowledge - that which we do not even (consciously) know exists.

Eraut noted that in any given situation 'multiple pathways are likely to be in use' in terms of explicit/implicit encoding and retrieval (2000). He used the exemplar of an encounter with a new situation which is similar to one previously experienced: this may result in a rapid response seemingly automatically generated, while awareness that this rapid response action might not be the best reaction leads to explicit checking of the options for response based on generalised knowledge (Eraut 2000). This means that investigating implicit learning can be complicated by the possible presence of explicit processes alongside it.

The approach taken by Eraut strongly implies that explicit and implicit processes, although related and potentially occurring simultaneously, are not simply extensions of the same thing. While contradicting Reber's original hypothesis that implicit learning and explicit learning were both part of one continuum, this is the approach adopted by more recent psychological research into implicit learning (e.g. Eraut 2000, Perruchet \& Vinter 2002, Henke et al. 2003) and as such will be the approach taken here.

As Evans noted, there is a 'growing recognition that the tacit dimensions of knowledge and skill are very important in the performance of individuals, organizations, networks and possibly whole communities,' (2002: 80-2). Evans and Rainbird stated that:

The part played by tacit skills and knowledge in work performance is well recognized but not well understood. These implicit or hidden dimensions of knowledge and skill are key elements of 'mastery', which experienced workers draw upon in everyday activities and continuously expand in tackling new or unexpected situations (Evans \& Rainbird 2002: 21).

There is a wide range of literature which places emphasis on the learning of skills within the museum environment (e.g. Enquire 2006) and the uniqueness of this environment when it comes to the development of a broad range of different skills (IMLS 2009). As such it is 
possible to see how implicit learning in museums could contribute towards the development of expert skills and knowledge, and how understanding implicit learning could ultimately lead to museum experiences which are more fulfilling and engaging:

Many psychological and educational theories conceive the art experience as constructive deployment of skill ... individual variations in such competence significantly determine the different levels of engagement (Kesner 2006: 5).

Kesner went on to describe a range of museum users: from those who visited repeatedly and could be described as 'skilled' to the casual consumers whose direct experiences of museum or art objects did not necessarily represent the focal point of a visit beyond the other recreational experiences on offer (2006: 5).

Although there are many overlaps between the theories of implicit learning expressed here, the key difference centres on process versus product. Reber's definition, and to some extent Eraut's, was concerned with the act of learning itself and which aspects relate to the definition 'implicit', while Dianne and Dienes were focused on the outcome: the response or behaviour of an individual. Pozzali pointed out that tacit knowledge research 'has always been more focused on the product (tacit knowledge) than on the process (tacit knowing)' (2008: 230).

I will take a broad approach in this paper which considers both the product and the process. In other words, rather than rule out either as potential examples of implicit learning, the method seeks to identify cases of knowledge which participants do not appear to know about (tacit knowledge), as well as evidence that knowledge acquisition may have been incidental or automatic (tacit knowing).

\section{Method}

In order to investigate implicit learning in museums/galleries a qualitative approach was implemented based around interviews with 'experienced' museum visitors.

Interviews were carried out with groups of people who had a wide range of museum experiences to draw upon: members of two gallery 'friends' associations. The secretaries of a number of associations were contacted and of the two that responded positively, individual interviewees were nominated based upon a short set of criteria. Interviewees had to have experience visiting a number of different museums/galleries; I asked that participants include both men and women; and participants had to be willing to be interviewed as part of the project.

These interviews focused on participants' experiences relating to museums and galleries, as well as their feelings/thoughts on such institutions and the act of visiting. Eight members of two groups (the Friends of the Laing Art Gallery and the Friends of the Shipley, two galleries in the North East of England) were identified, four people from each group. All names have been anonymized and quotations are identified through a numbering system (1-4) for either interviewees from the 'Laing' or the 'Shipley'. More information about the participants is included in the Appendix.

Researching implicit learning is a problematic task, given that by its very nature, tacit knowledge is silent. Frensch noted that 'verbal reports, be they free recall or cued recall, are often unreliable and invalid measures of consciousness' (1998: 62), in other words: that which can be gleamed from interviews may not necessarily show whether or not something is conscious/unconscious/subconscious. However, I would argue that verbal reports are not entirely invalid and can be a potentially useful indicator of what an individual may or may not have learnt/gained from an experience, so long as they are treated with care (see for example Diamond et al. 2009).

The majority of studies which investigate implicit learning do so in laboratory conditions, controlling the information participants receive in order to test their subsequent use of it (e.g. Perruchet \& Vinter 2002). Acommon experiment in psychological research is known as 'artificial grammar learning' and exposes subjects to strings of letters governed by hidden rules and other strings which are totally random (and told that the first set are 'grammatical' and the second set are not). They are then shown further, new, sets of letters and asked to indicate which are grammatical and which are not. Subjects can usually perform at an above-chance level in terms of deciding which strings are grammatical - without being able to describe which 
rules the strings adhere to, or why one string is grammatical and another is not (e.g. Pozzali 2008). In real-world settings it is much more difficult to research the concept: there are many more variables and external influences than the abstract situations employed in laboratory research. Eraut points out many of the problems inherent in researching implicit learning in a 2004 paper, but recognizerecognizes that interviews which do not focus on atypical situations or on 'learning' itself are often the best way to collect data on participant's learning activities.

In this paper, in order to identify potential cases of implicit learning, analysis of interview data has focused on individual interviews: attempting to find instances of participants saying one thing which is then later contradicted. The logic behind such an approach centres on the idea that if a participant is unaware that they have learnt something they may deny knowledge of it. In the artificial grammar learning experiment (above) it is possible to ensure that participants do not know they are learning grammatical rules by keeping such rules obscured - in museum (and indeed all 'real-world') settings it is not possible to exert such control. However, by identifying instances of participants saying one thing, and then contradicting themselves, this might indicate that they were unaware of the knowledge they expressed.

Although the author is unaware of directly comparable approaches in the field, Felstead et al.'s research into learning in the workplace acknowledged the need to investigate the problem circuitously through discussion of individual's activities without any mention of the term 'learning' (2004).

Issues which need to be considered include the fact that what are essentially being compared/analysed are the verbal reports of participants, which may not necessarily reflect reality. Given that there is a view that 'certain kinds of human knowledge [are] ... difficult or impossible to verbalise and delimit' (Bjørnåvold 1997: 64), which may include implicit learning, research methodologies need to acknowledge the inherent limitations that apply to conclusions. Participants may not always recount information or experiences accurately and may be affected by the context and the presence of a researcher (Keegan 2009: 82), 'researchers need to be aware of the potential of data collection methods, interventions and themselves to profoundly (and substantially) influence participants metacognition' (Anderson et al. 2009: 192); especially relevant when considering the links between implicit learning and metacognition (see Dienes \& Perner, 2002).

\section{Results}

The following excerpts, and analyses, relate to examples of contradiction and what this might reveal about subjects' implicit learning. The section is in two parts, the first of which focuses on examples of knowledge which participants seemed to be unaware of. Interviews were analysed to find instances of participants claiming not to know something and then demonstrating that very knowledge.

The second section turns its attention to potential instances of unconscious learning (resulting in conscious knowledge). In this case, interviews were analysed in order to find examples of participants demonstrating knowledge, but being seemingly unaware of how they gained such knowledge.

One of the most obvious examples of the former occurred when one participant, after being asked about how she views museums and galleries, replied that

'In a museum it's an object; where you don't, you don't feel anything about it' (Laing2),

while then stating, later on in the interview, that museums were:

A collection of objects: some of them interesting. The most interesting museums you actually get to touch but that's very unusual ... it's stuff from the past, you can see things that were in your own home when you were younger, like, go to Beamish, you know, you can see, my grandma had one of those. It's just, it's nice to see things from the past, and nice to see how things from the past look, modern, look, don't mean modern ... contemporary, no not contemporary, because that's ... you know they wouldn't look out of place nowadays, it's just interesting 
and I like to take my granddaughter, because she gets fascinated by things like that (Laing2).

Although originally advocating for a view that museums, and their objects, were not something you could feel emotions about, the participant actually related some incredibly emotive episodes, including seeing things that reminded her of her past (her grandma) and using words/phrases like 'interesting'; 'nice to see'; and 'fascinated' to describe her and her granddaughters' reaction to museum objects. While explicitly coming to the conclusion that she felt one way about objects in museums/galleries, the way she retold narratives about actual visits, in particular with regard to the language she used, but also her demeanour, which was often expressive and enthusiastic, suggested that subconsciously she felt something different.

Another participant, when asked why she was interested in museums/galleries (an assumption based upon her membership of the group) and whether her upbringing had played a role, responded that: 'no, I think it's just an innate interest' (Laing4). Such a belief - of an interest being simply innate - suggests that she was not aware of any prior influence on her current habits/interests. Yet, later on in the interview, when asked about her childhood, she related a number of occasions when she was taken to museums/galleries by her grandfather, stating that:

You know, when I was very little. It was very much of a, things in wooden cases, but you know, I was a sort of boring, geeky child that just loved, looking in, you know, boring wooden cabinets. I didn't need things to play with (Laing4).

She spoke with genuine fondness regarding these experiences, and although it is not conclusive, I would suggest that this prior experience, interest, and love of museums may well have played a part in her interest later in life. She was seemingly not aware of this relationship (believing the interest to be 'innate') and yet it most probably existed. Oskala et al. found that those who had attended/participated in the arts when growing up had a 'significantly higher chance of being an active arts consumer as an adult' (2009: 5).

Similarly, another example of potentially 'unconscious' knowledge can be found in a different interview in which a participant talked about his involvement with the gallery

'It's a practical side to it, that's what I do, I mean I don't go and say oh, I like this, or I like that, and I do this, that's not my, that's not my field' (Shipley2).

Specifically, he said he was involved with the 'practical side' and referenced helping out the friends group in terms of their finances and accounts. He claimed not to possess any art-related knowledge and claimed not to express likes/dislikes when it came to art either. However, in reality he actually displayed a high level of knowledge, using appropriate terminology (he referred to the 'Impressionists'), knowing the names of artists (referencing Claude Monet and John Singer Sargent amongst others) and knowing when particular exhibitions would be on, and where (he spoke of a watercolour exhibition at Tate Britain that he intended to visit). Furthermore he also did express likes and dislikes and explained his interests:

If you look, if you look at the pictures you know, you can relate it to your home environment, you know, this is where my dad was, so it's things like that, that's my interest. The, this idea of, erm, I mean that's why modern art is, I find it sometimes difficult (Shipley2).

It is possible that this response was motivated by a sense of modesty, or was due to the presence of an interviewer, however it could equally be suggested that he was simply unaware of his own ability and his own response. In reality it is probably a combination of the two: the participant was both deliberately underplaying his own knowledge, but also unintentionally underestimating it. Implicit learning, in this case, may help explain the unconscious/tacit knowledge which this participant possessed in terms of both art historical 'facts', but also his ability to explain why he liked/disliked particular artworks. 
There are examples of people claiming a lack of knowledge but then actually demonstrating the knowledge which they have previously denied. While this may be caused by factors such as modesty and the effect that the presence of a researcher/the context may have had, there is also the potential that participants were unaware of the range of knowledge they possessed: they had learnt it unintentionally and/or unconsciously. One interviewee said

'And, you know, I like looking at art, I mean I don't say I'm all that knowledgeable about it, I mean, I know what I like, you know' (Laing1).

However, later in the interview, when asked to describe a recent visit to a museum or gallery, she talked at length about a visit and demonstrated a broad level of knowledge which related both to the historical aspects of her visit (and the artist involved) and artistic ones:

\begin{abstract}
Yeah, well of course we've just come back from, like I say, near Windsor and we went to the Sandham Memorial Chapel, that Stanley Spencer designed and then painted the whole interior. It's an absolutely fantastic place, there's only natural light coming in through one window, just above the doors. So they say the best time to visit is sort of late morning, early afternoon, cus then you get the light coming through properly. And we were very fortunate, I mean we were late morning, but it was sunny, and a few years ago they'd just cleaned the whole place, so the colours ... And it's the history of the First World War, from the basic soldier, you know, not the officers and things but what the ordinary soldier did and it's all these different scenes depicted. I thought it was fantastic and I think it took him six years to do. And at the end of it he must have had a wonderful sense of achievement to look round, at this wonderful, you know, because I would love my grandson to see that, to see how the First World War, the ordinary things like, with their kitbags (Laing1).
\end{abstract}

The participant spoke about the way the light affected the viewing experience; she detailed some history of the gallery ('a few years ago they cleaned the whole place') and how this affected the colours; as well as explaining what had motivated the artist and exactly what he had depicted (in terms of the First World War). As well as demonstrating knowledge relating to a number of visit aspects she also demonstrated a depth of knowledge and showed evidence of knowledge synthesis: putting together elements to form meaning (Bloom 1956). Although this level of knowledge clearly developed out of a specific gallery visit, the lengthy description provides evidence that the participant's original comment, about not being 'all that knowledgeable', is at least debatable. It is unclear whether her assertion that she wasn't 'knowledgeable' was due to a lack of appreciation of the knowledge she possessed, or whether she perceived the term as implying a certain level of advanced knowledge (particularly given the context of being interviewed by a researcher). Similarly another interviewee believed that 'you have to particularly go down that road and research it and study it if you want to get anything from it' when talking about contemporary art (Laing3), suggesting that for some of these participants, the concept of expertise was reserved for those that actively studied or researched their topic.

One interviewee commented on her lack of knowledge/her inability to remember specific facts: 'I can't remember the names of artists!' (Laing2). Yet, during the interview, she recalled artist names on at least three separate occasions:

Or they'll say, "Oh I really want to see such and such, do you fancy coming with us?" Like Joe Cornish, someone said, I really want to go see that so we all went, you know (Laing2).

And I was never that, I was never that interested, where did we go, the Gaudi ... I think it might have been Gaudi museum (Laing2).

I hate, don't know if there's a favourite artist, depends on who l've last seen. I mean I love the John Martin's [at the Laing], they're impressive, but I don't love all John Martin's work (Laing2). 
These recollections, once again, suggest that in this case the participant had experienced implicit learning: either learning this information without realizing it, or no longer being aware of the knowledge she possessed until required to directly use it.

The majority of the examples explored so far have concentrated on, or at least been potential cases of, knowledge which those involved were unaware of but were able to relate if prompted correctly. However, the following quotation gives an insight into a case of learning which itself is unconscious, but which results in conscious knowledge. The interviewee spoke about recognizing when something was different or out of place at a National Trust property (Wallington) which she regularly visited

'Erm, it's sort of, really it's like visiting old friends, because I know the house pretty well, but there's always, you can always spot something different, some detail in the paintings in the hall, or some new object' (Laing4).

The participant made a point of saying that she did not actively seek out learning opportunities when she visited, preferring, instead to go because she enjoyed the surroundings and in order to have a coffee in an environment she liked. However, she was able to notice when something changed, suggesting that implicitly she recognized the original 'pattern' of objects and pictures; 'implicit learning may help us to pick up repeated patterns or relationships among stimuli or events, and by doing so help direct our conscious learning processes towards interesting features of our environment' (Braisby \& Gellatly 2005: 560). Ziori and Dienes explained how implicit processes are able to 'take over' once a certain level of proficiency is reached:

Maybe, for example, at an early stage of learning the explicit component dominates, as people try to apply rules and explain conceptual relations, but with increased experience, the implicit component takes over, as past exemplars are easily retrieved from memory (Ziori \& Dienes 2007: 621).

Another participant suggested that when visiting galleries with friends, they would often talk about what they liked/did not like and try to reach conclusions regarding people's tastes:

We would always decide who liked what, so people would, they would say they liked this and we would try to arrive at a reason. And, we would try to each appreciate the others' particular thing that they took us all to see. So I suppose trying to formulate what their likes and dislikes were (Shipley4).

However, she expressed doubt as to whether they were able to reach satisfactory conclusions (in terms of why they liked specific things) and noted the fact that when visiting with her friends, people would often have to compromise in terms of what exhibitions/galleries were visited. There is a belief that implicit learning may help people to formulate likes and dislikes, through its association with a 'phenomenal sense of intuition' (Berry 1996: 220) without necessarily being able to say why/explain their choices:

That is, people do not feel that they actively work out the answers. Rather, that they make particular responses because they 'feel right', or typically they may simply believe that they are guessing (Berry 1996: 220).

Essentially, that is to say, they are unaware why they feel one way or another (and are unable to rationalize their decisions/opinions).

It is worth discussing personal connections that visitors may have with museum objects or displays and their potential relation to implicit learning. Paris and Mercer broached the topic: 'we suggest that visitors are often guided implicitly to recognize or search for personal connections with objects, the Me-self features of their own identities' (2002: 403). Meanwhile, one of the most pertinent quotations that resonates with this argument comes from a former museum director who was one of the interviewees and who talked at length about the connections he drew with an exhibition of George Shaw:

Because I haven't seen an exhibition of his work previously, and, you know, I was really impressed, because it's a kind of landscape, that I was kind of brought up 
with, you know, it's the hinterland between the new housing estates in the 50 s and how they kind of crumbled ... I found these incredibly moving pictures, which he'd done in Humbrol enamel because it was the enamel that he used to make models and it was, very much a working, what he would describe as a working class thing to do (Shipley1).

The participant talked about the connections to his own childhood (identifying a landscape he was 'brought up with') that he drew with the work by Shaw. His appreciation for the pictures was in some ways regulated by the fact that he found the subject matter and even technique, the use of paints which were 'working class', relevant. The interviewee's interest in these pictures was highly motivated by the personal connections he made, which may have been guided implicitly.

While this section does not provide conclusive proof of implicit learning, it was never likely to be able to do so, and as such has instead sought to highlight potential cases of implicit learning, and suggest how participant responses might be understood in terms of how they fit into this aspect of Eraut's typology of non-formal learning (2000).

\section{Discussion}

Implicit learning is an entirely different form of learning, although that is not to say that explicit and implicit processes do not affect and influence each other. Identifying cases of implicit learning in the interview data has been one of the challenges of the research and, as the previous section showed, while it is extremely difficult to isolate definitively implicit examples of learning, it has been possible to suggest instances which may have involved either unconscious learning in the first place, or which may have resulted in tacit/unconscious knowledge.

Inherent problems with methods which utilize verbal report as their primary means of gathering information (e.g. Frensch 1998) mean that this particular aspect of the project may have been better served through data collection methods which, for instance, involved visitor observation (during museum/gallery visits). In particular, observation combined with interviews, or more creative forms of observation/interaction with visitors (e.g. the RCMG studies from 2001 which involved researchers accompanying visitors during visits and asking them to 'think aloud' and talk about what they saw, thought and felt) may provide better ways to study implicit, and by association non-formal learning.

Nonetheless, the methods outlined here and demonstrated through analysis of interviews with museum/gallery visitors do show that it is possible to identify potential cases of implicit learning and might serve as a blueprint for future work in the area. While this small scale study may not have provided conclusive proof of the role implicit learning plays in terms of the visiting habits of individuals, it is indicative of the presence of implicit learning, in one form or another.

There remains the question of whether implicit learning is characterized by an unconscious learning process, or simply results in knowledge which is tacit. Although there has been considerable debate in the literature, I would suggest that both instances could be classified as implicit without compromising the validity of the term. Indeed, given the difficulties associated with identifying unconscious learning/knowledge at all, it is perhaps not conceivable at this stage that the two could be properly and confidently differentiated.

\section{Conclusion}

The research method employed in this study-identifying instances of disparity within participants' recollections - highlighted examples of contradiction and changing perceptions for many of the participants. These experienced and regular museum/gallery visitors demonstrated many potential cases of implicit learning - suggesting that they may well have learnt things without realizing it during their visits.

The next step for such a research method (and for ultimately understanding the way visitors learn implicitly) would be to develop it further and test it out as part of a mixed methods approach - to see whether such behaviour is symptomatic of a wider group of museum visitors and to begin to establish how a deeper understanding of these processes might actually be of benefit to museum or gallery curators and educators. 
Submitted: 5 June 2014

Finally Accepted: 10 November 2015

\section{Notes}

1 The two 'Friends' groups in question both involved members paying a fee to join in return for invitations to special events and exhibitions, certain discounts etc. Both groups also involved members volunteering at the museum/gallery in question.

2 http://www.twmuseums.org.uk/laing/about/

3 http://www.twmuseums.org.uk/shipley/about/

4 http://www.shipleyfriends.co.uk/membership.html

\section{References}

Anderson, D., Nashon, S. \& Thomas G. (2009) 'Evolution of Research Methods for Probing and Understanding Metacognition.' Research in Science Education 39 (2), 181-195

Berry, D. (1996) 'How Implicit is Implicit Learning?' In Underwood, G. (ed.) Implicit Cognition New York: Oxford University Press

Bjørnåvold, J. (1997) 'Assessment of Non-Formal Learning: The Quality and Limitations of Methodologies.' European Journal of Vocational Training 12 (3), 52-67

Bloom, B. (1956) Taxonomy of Educational Objectives New York, Longman

Braisby, N. \& Gellatly, A. (eds.) (2005) Cognitive Psychology Oxford: The Open University Press

Buchner, A. \& Wippich, W. (1998) 'Differences and Commonalities Between Implicit Learning and Implicit Memory.' In Stadler, M. \& Frensch, P. (eds.) Handbook of Implicit Learning Thousand Oaks CA: Sage, 3-46

Diamond, J., Luke, J. \& Uttal. D. (2009) Practical evaluation guide: tools for museums and other informal educational settings Maryland: AltaMira Press

Dianne, B. \& Dienes, Z. (1993) Implicit Learning: Theoretical and Empirical Issues Hillsdale $\mathrm{NJ}$ : Lawrence Erlbaum Associates

Dienes, Z. \& Perner, J. (2002) 'A Theory of the Implicit Nature of Implicit Learning.' In French, R. \& Cleeremans, A. (eds.) Implicit Learning and Consciousness Hove: Psychology Press, 68-92

Enquire (2006) Inspiring learning in galleries London: engage

Eraut, M. (2000) 'Non-Formal Learning, Implicit Learning and Tacit Knowledge in Professional Work.' In Coffield, F. (ed.) The Necessity of Informal Learning Bristol: The Policy Press

Eraut, M. (2004) 'Informal Learning in the Workplace.' Studies in Continuing Education 26 (2), 247-273

Evans, K. \& Rainbird, H. (2002) 'The Significance of Workplace Learning for a 'Learning Society'.' In Evans, K., Hodkinson, P. \& Unwin, L. (eds.) Working to Learn London: Kogan Page, 7-28 
Evans, K. (2002) 'The Challenges of 'Making Learning Visible': Problems and Issues in Recognizing Tacit Skills and Key Competencies.' In Evans, K., Hodkinson, P. \& Unwin, L. (eds.) Working to Learn London: Kogan Page, 79-94

Falk, J. \& Dierking, L. (2000) Learning from Museums: Visitor Experiences and the Making of Meaning Maryland: AltaMira Press

Felstead, A., Fuller, A., Unwin, L., Ashton, D., Butler, P., Lee, T. \& Walters, S. (2004) 'Exposing learning at work: Results from a recent survey.' Paper presented to the Work, Employment and Society Conference, UMIST, 1-3 September 2004

Frensch, P. (1998) 'One Concept, Multiple Meanings.' In Stadler, M. \& Frensch, P. (eds.) Handbook of Implicit Learning Thousand Oaks CA: Sage, 47-104

Henke, K., Treyer, V., Nagy, E., Kneifel, S., Dursteler, M., Nitsch, R. \& Buck, A. (2003) 'Active Hippocampus during Nonconscious Memories.' Consciousness and Cognition 12, 31-48

Hooper-Greenhill, E., Dodd, J., Moussouri, T., Jones, C., Pickford, C., Herman, C., Morrison, M., Vincent, J. \& Toon, R. (2003) Measuring the Outcomes and Impact of Learning in Museums, Archives and Libraries https://www2.le.ac.uk/departments/ museumstudies/rcmg/projects/lirp-1-2/LIRP\%20end\%20of\%20project\%20paper.pdf

IMLS (2009) Museums, Libraries and $21^{\text {st }}$ Century Skills http://www.imls.gov/assets/1/ AssetManager/21stCenturySkills.pdf

Keegan, S. (2009) Qualitative Research: Good Decision Making Through Understanding People, Cultures and Markets London: Kogan Page

Kesner, L. (2006) 'The Role of Cognitive Competence in the Art Museum Experience.' Museum Management and Curatorship 21 (1), 4-19

Leinhardt, G. \& Knutson, K. (2004) Listening in on museum conversations. Oxford: AltaMira

Oskala, A, Keaney, E., Chan, T. \& Bunting, C. (2009) Encourage Children Today to Build Audiences for Tomorrow http://www.artscouncil.org.uk/publication archive/ encourage-children-today-to-build-audiences-for-tomorrow

Paris, S. \& Mercer, M. (2002) 'Finding Self in Objects: Identity Exploration in Museums.' In Leinhardt, G., Crowley, K. \& Knutson, K. (eds.) Learning Conversations in Museums Hillsdale NJ: Lawrence Erlbaum Associates, 401-423

Perruchet, P. \& Vinter, A. (2002) 'The Self-Organising Consciousness: A Framework for Implicit Learning.' In French, R. \& Cleeremans, A (eds.) Implicit Learning and Consciousness Hove: Psychology Press, 41-67

Pozzali, A. (2008) 'Tacit Knowledge, Implicit Learning and Scientific Reasoning.' Mind Soc. $7,227-237$

RCMG (Research Centre for Museums and Galleries) (2001a) Meaning Making in Art Museums 1: Visitors' Interpretive Strategies at Wolverhampton Art Gallery http:/l www.le.ac.uk/ms/research/pub1126.html

RCMG (2001b) Meaning Making in Art Museums 2: Visitors' Interpretive Strategies at Nottingham Castle Museum and Art Gallery http://www.le.ac.uk/ms/ research/pub1109.html 
Reber, A. (1993) Implicit Learning and Tacit Knowledge: An Essay on the Cognitive Unconscious New York: Oxford University Press

Silverman, D. (2005) $2^{\text {nd }}$ edn. Doing Qualitative Research London: Sage Publications

Ziori, E. \& Dienes, Z. (2007) 'How Does Prior Knowledge Affect Implicit and Explicit Concept Learning?' The Quarterly Journal of Experimental Psychology 61 (4), 601-624

\section{Appendix}

\section{Friends of the Laing Art Gallery}

The Laing Art Gallery is located in the centre of Newcastle-upon-Tyne and contains 'historic, modern and contemporary art'. ${ }^{2}$ The gallery is managed by Tyne and Wear Archives and Museums on behalf of Newcastle City Council. The friends association costs $£ 12$ to join (annually) and is a large organisation with a number of committees and sub-committees.

The following members were interviewed as part of this research:

- Laing1: A retired female, aged 65 years old.

- Laing2: A retired female, aged 64 years old.

- Laing3: A retired female, aged 68 years old.

- Laing4: A retired female, aged 63 years old.

\section{Friends of the Shipley}

The Shipley Art Gallery is located in Gateshead and describes itself as 'a national centre for contemporary craft' while also boasting 'a spectacular collection of fine art'. ${ }^{3}$ The Shipley is managed by Tyne and Wear Archives and Museums on behalf of Gateshead Council. The friends association is much smaller than the Laing's with only one regular committee and costs $£ 10$ to join annually. ${ }^{4}$

The following members were interviewed as part of the research:

- Shipley1: Retired male, aged 70 years old.

- Shipley2: Retired male, husband of Shipley3, aged 66 years old.

- Shipley3: Female housewife, wife of Shipley2, aged 66 years old.

- Shipley4: Working female, aged 55 years old.

*Dr Alex Elwick is a research officer at CfBT Education Trust (an education charity and multi-academy trust based in Reading, England). He completed his AHRC-funded PhD on 'non-formal learning in museums and galleries' at Newcastle University in 2013 where he also worked as a university teacher. He has undertaken a UK Research Councils' sponsored fellowship at the Library of Congress, Washington DC, and published work on topics including the UK digital divide and the success of London schools. He is an Associate Fellow of the Higher Education Academy.

10 Maple Drive

Gedling

Nottingham

NG4 4AF

alex.elwick@gmail.com

07841586270 
